\title{
A matemática em atividades interdisciplinares: uma base para a estruturação dos Seminários Integrados
}

\author{
The mathematics in interdisciplinary activities: a basis for structuring \\ in Integrated Seminars
}

\author{
Mauro Dinael Beielfuss Bartz ${ }^{1}$, Cinthya Maria Schneider Meneghetti ${ }^{2}$ e \\ Cristiana Andrade Poffal ${ }^{3}$ \\ 1,2,3 Universidade Federal do Rio Grande ,FURG - S, RS, Brasil
}

\begin{abstract}
Resumo
A partir do ano de 2012, lança-se uma proposta de reestruturação no Ensino Médio no Estado do Rio Grande do Sul, na qual surge um elemento novo na grade curricular chamado de Seminário Integrado. Esse tem por objetivo aliar a formação geral à parte diversificada do currículo através de um planejamento interdisciplinar voltado à pesquisa. Diante desse cenário aparece a motivação para elaborar esse trabalho, nele apresentam-se três atividades interdisciplinares relacionando a matemática com outras disciplinas. Nossa proposta é que elas possam servir como uma possivel base para elaboração elou estruturação dos Seminários Integrados. Junto com cada atividade apresentamos uma proposta de pesquisa relacionada à prática social, bem como em quais sentidos elas poderão preparar o jovem para ser inserido no mercado de trabalho. O material elaborado pelos professores envolvidos e a escolha dos métodos de ensino utilizados são subsidiados por uma pesquisa bibliográfica que fizemos a respeito do tema interdisciplinaridade. As atividades elaboradas foram aplicadas em duas turmas de terceiro ano do Ensino Médio, em uma escola particular na cidade de Pelotas, Rio Grande do Sul. Apresentamos alguns dados que consideramos relevantes em termos de resultados relacionados ao ganho pedagógico.
\end{abstract}

Palavras-chave: Interdisciplinaridade, Contextualização, Seminário Integrado.

\begin{abstract}
In 2012 came a proposal for restructuring the high school in the state of Rio Grande do Sul, known as Integrated Seminar. This aims to assess general education to diverse part of the curriculum through an interdisciplinary planning of directed researching. In this scenario, here comes the motivation to prepare this work. This study presents three interdisciplinary activities relating mathematics to other disciplines. Our proposal is that these activities may serve as a possible basis for preparation and/ or structuring activities in Integrated Seminars. Along with every activity, we propose a social practice related to research as well as in which way these activities will prepare the young to be inserted in the labor market. The material prepared by the teachers involved and the choice of teaching methods used is subsidized by a literature research we performed on the subject about interdisciplinary. The activities were implemented in two classes of third year of high school, in a private school in the city of Pelotas, Rio Grande do Sul. We also present some data that we consider relevant in terms of pedagogical gain.
\end{abstract}

Keywords: interdisciplinary; contextualization; Integrated Seminar. 


\section{Introdução}

Este trabalho foi motivado pela falta de situações contextualizadas que envolvam a aplicabilidade dos conceitos estudados na sala de aula. Esse problema leva muitos estudantes a questionar sobre o estudo da matemática, a saber: "Onde irei aplicar isso na minha vida?"

Pela forma tradicional de ensino, a sala de aula é um ambiente onde o professor expõe o conteúdo transmitindo seus conhecimentos sendo os alunos meros expectadores. Em especial, nas aulas de matemática, poucos são os momentos onde ocorrem debates ou questionamentos a respeito de qualquer assunto relacionado à matéria que está sendo estudada.

Uma das principais consequências dessa problemática é o despreparo dos estudantes para ingressarem no mercado de trabalho. Saviani (2007) afirma que, no Ensino Médio, "a relação entre educação e trabalho, entre o conhecimento e a atividade prática deverá ser tratada de maneira explícita e direta" e que o "papel fundamental da escola de nível médio será, então, o de recuperar essa relação entre o conhecimento e a prática do trabalho". Uma carreira de sucesso, na grande maioria das vezes, requer que o indivíduo tenha pensamento crítico, habilidade de trabalhar em equipe e saiba se comunicar adequadamente. É importante também que o indivíduo seja capaz de lidar com situações problemas, sem uma solução que esteja pronta. Notamos, todavia, que a escola tem contribuído muito pouco para o desenvolvimento dessas habilidades.

No âmbito do ensino da matemática, percebemos que não será possível uma mudança significativa se continuarmos com o modelo atual de práticas pedagógicas, baseadas em um currículo fragmentado. Nesse paradigma de mudança, e buscando a aproximação entre o Ensino Médio e práticas que oportunizem a qualificação do estudante para o mercado de trabalho, a Secretaria de Educação do Estado do Rio Grande do Sul SEDUC/RS (2011-2014a) introduz no Ensino Médio um novo componente curricular, denominado Seminário Integrado, com $\mathrm{o}$ foco voltado à pesquisa e à interdisciplinaridade.

Conforme SEDUC/RS (2011-2014a) com os Seminários Integrados busca-se preparar o aluno para o desenvolvimento científico e tecnológico, aliando a integração de conhecimento com práticas voltadas à sua realidade.

Para minimizar a distância que existe entre o ensino de matemática atual e aquele que consideramos desejável, propomos atividades práticas contextualizadas, voltadas à interdisciplinaridade.

Vale destacar que, para Fazenda (2011):

O professor interdisciplinar é um ser que busca, pesquisa, tem compromisso com seus alunos, identifica-se como alguém insatisfeito com o que realiza, enfim, é um profissional que luta por uma educação melhor e busca por projetos interdisciplinares em diversas áreas do conhecimento.

Como objetivo principal, apresentamos neste trabalho três propostas de atividades interdisciplinares, as quais podem ser aplicadas em sala de aula na forma como estão apresentadas ou servirem como uma possível base para a estruturação de Seminários Integrados.

Para construir este artigo, nos baseamos nos trabalhos desenvolvidos por Fazenda (2011), SEDUC/RS (2011-2014a), Saviani (1989) e BRASIL (2000), cuja análise constitui os pressupostos teóricos referentes ao tema interdisciplinaridade bem como a metodologia aplicada em nossas atividades.

\section{Reestruturação do Ensino Médio}

Em 2011, a SEDUC/RS apresentou à população gaúcha uma Proposta de Reestruturação Curricular para o Ensino Médio, onde um dos objetivos foi mudar a realidade do currículo fragmentado e dissociado da realidade dos alunos, que apresentavam altos índices de reprovação. Dessa forma, conforme SEDUC/RS (20112014a), pretende-se resgatar à vida escolar 84 mil jovens entre 15 e 17 anos que atualmente estão fora da escola.

A Lei de Diretrizes e Bases da Educação Nacional (LDB 9394/96) estabelece o Ensino Médio como etapa final da Educação Básica, cujo objetivo principal é preparar o indivíduo para o exercício da cidadania e para o seu desenvolvimento pessoal, fornecendo meios para progredir no trabalho e em estudos posteriores. Com essa reestruturação no estado do Rio Grande do Sul, a etapa final da Educação Básica ficou organizada como Ensino Médio Politécnico, Ensino Médio Curso Normal e Educação Profissional Integrada ao Ensino Médio.

Conforme Pereira (2012), justifica-se a importância do projeto do Estado do RS, considerando a baixa qualidade de ensino no Brasil e a necessidade de propostas que venham mudar este quadro. A última etapa da Educação Básica, o Ensino Médio, na rede estadual, não foge à regra em termos de baixo rendimento escolar, o que pode ser visualizado no baixo Índice de Desenvolvimento da Educação Básica, IDEB, conforme os dados obtidos em PORTALIDEB (2014) e apresentados no gráfico da Figura 1.

Segundo a Organização das Nações Unidas para a Educação, a Ciência e a Cultura, UNESCO, o recomendável é um IDEB 6, o que deixaria o Brasil no mesmo nível que os países da Organização para Cooperação e Desenvolvimento Econômico, OCDE. Mas, analisando o gráfico da Figura 1 percebemos que estamos abaixo do que se propõem. Alarmantes também são as metas propostas, indicativos de que mudanças são necessárias. 


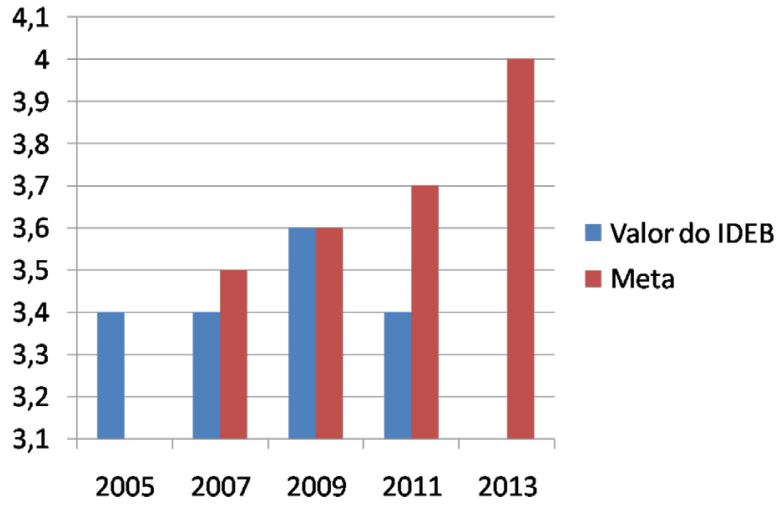

Figura 1: Metas para os valores do IDEB no Estado do Rio grande do Sul

Com o objetivo de mudar esses índices, implantou-se a partir do ano de 2012, o Ensino Médio Politécnico. Nessa nova modalidade vale destacar as seguintes mudanças:

- a implantação do novo sistema foi gradativa, começando com o $1^{\circ}$ ano reformulado em 2012, o $2^{\circ}$ ano, em 2013 e o $3^{\circ}$, em 2014;

- as disciplinas tradicionais foram divididas em quatro grandes áreas de conhecimento e agrupadas da seguinte forma: linguagens (língua portuguesa, literatura, educação física e artes), matemática, ciências da natureza (biologia, física e química) e ciências humanas (história, geografia, sociologia e filosofia) que compõem a formação geral, e Seminário Integrado, língua estrangeira e ensino religioso, na parte diversificada;

- a avaliação passou a ter um novo modelo, no qual as notas de zero a dez forão substituídas por conceitos descritivos: Construção Satisfatória da Aprendizagem (CSA), Construção Parcial da Aprendizagem (CPA) e Construção Restrita da Aprendizagem (CRA). Os dois primeiros permitem a aprovação. Se o estudante apresentar desempenho insatisfatório em apenas uma área do conhecimento, poderá passar de ano, num regime de progressão parcial. Caso o aluno receba conceito CRA em pelo menos duas áreas de conhecimento, será reprovado. Os conceitos serão atribuídos por áreas e não mais por disciplinas isoladas. Cada aluno terá, portanto, quatro conceitos, estabelecidos a partir do consenso entre os professores envolvidos em cada área de conhecimento;

- a carga horária foi ampliada. Das 2.400 horas/aula anteriores, o Ensino Médio Politécnico passa a ter um total de 3.000 horas/aula, sendo 1.000 horas/aula para cada ano. Essas horas foram distribuídas nas áreas formação geral e parte diversificada, conforme Tabela 1.

Tabela 1: Distribuição da carga horária nos 3 anos do Ensino Médio

\begin{tabular}{lllll} 
& $1^{\mathrm{o}}$ ano & $2^{\circ}$ ano & $3^{\circ}$ ano & TOTAL \\
\hline F. Geral & $750 \mathrm{~h}$ & $500 \mathrm{~h}$ & $250 \mathrm{~h}$ & $1.500 \mathrm{~h}$ \\
P. Diversificada & $250 \mathrm{~h}$ & $500 \mathrm{~h}$ & $750 \mathrm{~h}$ & $1.500 \mathrm{~h}$ \\
TOTAL & $1.000 \mathrm{~h}$ & $1.000 \mathrm{~h}$ & $1.000 \mathrm{~h}$ & $3.000 \mathrm{~h}$ \\
\hline
\end{tabular}

É importante destacar que pelo Regimento Referência SEDUC/RS (2011-2014b) a proporcionalidade de distribuição das cargas horárias dos dois blocos formação geral e parte diversificada não é rígida, podendo adaptar-se conforme o projeto político pedagógico da escola. Essa divisão tem por objetivo assegurar um processo de ensino e aprendizagem contextualizado e interdisciplinar.

\section{Seminários Integrados}

A prática docente mostra que os Seminários Integrados talvez sejam a maior surpresa nessa nova proposta de ensino no Estado do Rio Grande do Sul. Para entendermos melhor o papel que ele desempenha no currículo, vamos analisar o que consta sobre este item na proposta da SEDUC/RS (2011-2014a),

\footnotetext{
O Seminário Integrado, que está localizado na parte diversificada, constitui-se em espaço planejado, com a participação de professores das áreas do conhecimento (formação geral) e alunos, realizados desde o primeiro ano e em complexidade crescente. Consta da carga horária da parte diversificada, proporcionalmente distribuída do primeiro ao terceiro ano.
}

As aulas referentes a este componente curricular devem ocorrer, preferencialmente, em turno inverso. Ainda segundo SEDUC/RS (2011-2014a), “Os projetos originados no Seminário Integrado são de responsabilidade do coletivo dos professores que atuam na formação geral, com a coordenação e o acompanhamento rotativo, oportunizando a apropriação e a construção coletiva da organização curricular".

Orientado pelo professor, no Seminário Integrado, o objetivo principal é que o aluno conduza um projeto de pesquisa, vinculado a uma das quatro áreas do conhecimento. 
Os projetos de pesquisa, quando elaborados, devem surgir de uma necessidade e/ou uma situação problema, que esteja relacionada a um dos seguintes eixos transversais:

1. Acompanhamento Pedagógico;

2. Meio Ambiente;

3. Esporte e Lazer;

4. Direitos Humanos;

5. Cultura e Artes;

6. Cultura Digital;

7. Prevenção e Promoção da Saúde;

8. Comunicação e Uso de Mídias;

9. Investigação no Campo das Ciências da Natureza;

10. Educação Econômica e Áreas da Produção.

Com essa análise é possível notar que o Seminário Integrado desempenha o papel de articulador, mobilizador e problematizador do currículo escolar. Ele constitui um espaço de integração dos conhecimentos formais com os conhecimentos e as realidades dos alunos, tornando-se essencialmente interdisciplinar.

\section{Referencial Teórico}

Qualquer problema sociocultural ou profissional diante de um indivíduo constitui uma questão complexa para trabalhar com a concepção meramente disciplinar. É por isso que a interdisciplinaridade tem sido muito discutida nos últimos anos na comunidade pedagógica. Por muito tempo estudiosos tentaram conceituá-la.

Em nossa pesquisa, observamos que o conceito mais usado é o elaborado por Japiassu (1976). Segundo ele, "A interdisciplinaridade caracteriza-se pela intensidade das trocas entre os especialistas e pelo grau de interação real das disciplinas no interior de um mesmo projeto de pesquisa". Essa definição está diretamente relacionada à proposta deste trabalho e foi com ela, que nos identificamos.

Para Saviani (1989) "é necessário superar a fragmentação, a superposição de conceitos, a desconexão entre teoria e prática", que é atualmente a marca presente no Ensino Médio com a divisão dos conteúdos feita por disciplinas.

De forma geral, muitos elementos têm influenciado a necessidade da reestruturação do currículo escolar, em especial, a rapidez das mudanças em todos os setores da sociedade atual (científico, cultural, tecnológico ou político-econômico), o acesso fácil e rápido a informação, as novas exigências do mercado de trabalho e, principalmente, as exigências no campo da pesquisa, da produção e da tecnologia. Fatores como esses, para Andrade (1994), "têm provocado uma revisão didático-pedagógica do processo de educação escolar".

Dessa forma,

Surge uma nova concepção de ensino e de currículo, baseada na interdependência entre os diversos campos de conhecimento, superando-se o modelo fragmentado e compartimentado de estrutura curricular fundamentada no isolamento dos conteúdos.(Andrade (1994))

\section{Atividades Interdisciplinares}

Nesta seção descreveremos de que forma foram elaboradas e quais os objetivos das atividades interdisciplinares que propomos e que podem servir de modelo para a elaboração de Seminários Integrados.

A aplicação ocorreu em uma instituição particular de ensino na cidade de Pelotas, RS. A duração da execução de cada uma das atividades foi de 3 períodos de 50 minutos.

\subsection{Análise histórica e aplicabilidade de par- tes do corpo como unidade de medida.}

Nesta atividade, relacionamos Matemática, História e Geografia. Descrevemos os tópicos abordados e os materiais necessários para a sua realização. Fornecemos um texto base, a fim de despertar a curiosidade e o interesse dos alunos. Após a leitura do texto, os professores por meio de debate e troca de conhecimento, devem apresentar os temas relacionados a cada disciplina. Neste trabalho descrevemos com detalhes a parte que cabe a matemática.

Em termos de continuidade dos estudos, no que se refere as disciplinas de Matemática e Geografia, o aluno realizará uma aula prática onde o objetivo será usar a medida do seu pé como unidade de medida, para efetuar cálculos de comprimento, perímetro de figuras geométricas e escalas. Para a disciplina de História propomos um trabalho de pesquisa a respeito da revolta do Quebraquilos, para entrega posterior, conforme orientações do professor.

Como Proposta de Intervenção Social lançamos um projeto de pesquisa a respeito da mobilidade urbana da cidade, que se encaixa no eixo transversal Educação Econômica e Áreas da Produção.

Descrição da Atividade: estudaremos as unidades de medidas no contexto de Matemática, Geografia e História. Cada área abordará os seguintes aspectos: 
* Matemática: usando a medida do comprimento do nosso pé, iremos construir funções matemáticas que possam determinar o perímetro de formas geométricas, em especial as que aparecem na quadra de esportes de nossa escola.

\& Geografia: estudaremos o conceito de escala cartográfica e suas aplicações, mais precisamente as escalas gráfica e numérica.

* História: estudaremos o papel dos escribas no Egito Antigo e a detenção deles sobre o poder das unidades de medidas. Relacionaremos a Revolução Francesa e os impactos do Iluminismo no estudo das Ciências.

\section{Objetivos:}

Conhecer as unidades de medida pé, polegada e jarda;

Obter uma aproximação para o número irracional $\pi$;

Calcular perímetro, diâmetro e raio da circunferência usando o pé como unidade de medida;

Formalizar o conceito de unidade de medida, sua origem e a evolução ao longo da história da humanidade, bem como sua importância em fatos como a Revolução Francesa;

Efetuar conversões de unidades;

Verificar que a ideia de escala consiste em estabelecer uma relação matemática ou numérica entre "dois mundos", ou seja, a relação entre o mundo real e o mundo da representação (mapas);

Criar escalas e usá-las para esboçar uma situação real.

Material necessário para a realização dessa atividade: Quadro branco, caderno, régua, lápis e borracha.

Motivação: Segundo Silva (2014), ao longo da história da humanidade as unidades de medida eram criadas e adaptadas para satisfazerem as necessidades básicas dos povos. Na grande maioria das vezes, para definir essas medidas eram tomadas como parâmetro partes do corpo de um membro da realeza (geralmente o rei). A padronização das unidades de medidas na Inglaterra só ocorreu no século XIII, quando um pé passou a ter 30,48 centímetros, independentemente do rei que estivesse no poder.

Atualmente, a medida oficial de um pé é doze polegadas - o tamanho médio dos pés masculinos adultos. Esse sistema de medida é utilizado atualmente no Reino Unido, nos Estados Unidos e, com menor frequência, no Canadá.

Definição 1. Um Pé (ou pés no plural) é uma unidade de medida de comprimento, corresponde a 30,48 centímetros ou 12 polegadas e 3 pés equivalem a 1 jarda.

$$
\begin{aligned}
& 1 \text { pé }=30,48 \text { centímetros }=12 \text { polegadas } \\
& \text { Notação: } 1 \mathrm{ft}=30,48 \mathrm{~cm}=12 \mathrm{in} \quad 3 \mathrm{ft}=1 \mathrm{yd}
\end{aligned}
$$

Para compreendermos o contexto histórico da necessidade do surgimento das unidades de medidas, bem como a variação delas através dos tempos e dos povos, apresentamos como sugestão de leitura o artigo Conheça a fascinante história das medidas, que acompanham o homem desde o tempo das cavernas, Vomero (2003). A Figura 2 apresenta uma síntese do artigo na forma de uma linha do tempo.

Após a leitura deste texto, sugerimos um pequeno debate antes de iniciar as questões práticas. Pergunte aos seus alunos se eles conhecem ou já usaram unidades de medida alternativa tais como: pés, palmos ou passos. Quais as principais dificuldades que aparecem quando optamos por esse sistema? Quais as vantagens?

Em seguida, convide a todos para dirigirem-se a quadra de esportes da escola.

\section{Questões Propostas aos Estudantes:}

Questão 1. Começaremos definindo o comprimento do seu pé pela variável $x$. Individualmente, determine o perímetro $Q(x)$ da quadra de esportes, o perímetro $C(x)$ do círculo central, o diâmetro $D(x)$ e o raio $R(x)$ do círculo central em função do comprimento $x$ de seu pé. Por exemplo, se o perímetro da quadra obtido foi $100 \mathrm{ft}$, escreva $Q(x)=100 x$. Um esboço da quadra de esportes pode ser visto na Figura 3. Com os dados obtidos, complete os quadros:

\begin{tabular}{|l|l|}
\hline$Q(x)=$ & $C(x)=$ \\
\hline$D(x)=$ & $R(x)=$ \\
\hline
\end{tabular}

a) Com as funções obtidas, determine o valor da razão $\frac{C(x)}{D(x)}$;

b) Com uma régua, determine a medida $x$ do seu pé em cm, colocando o resultado no quadro a seguir;

Medida do pé em $\mathrm{cm}=$ 


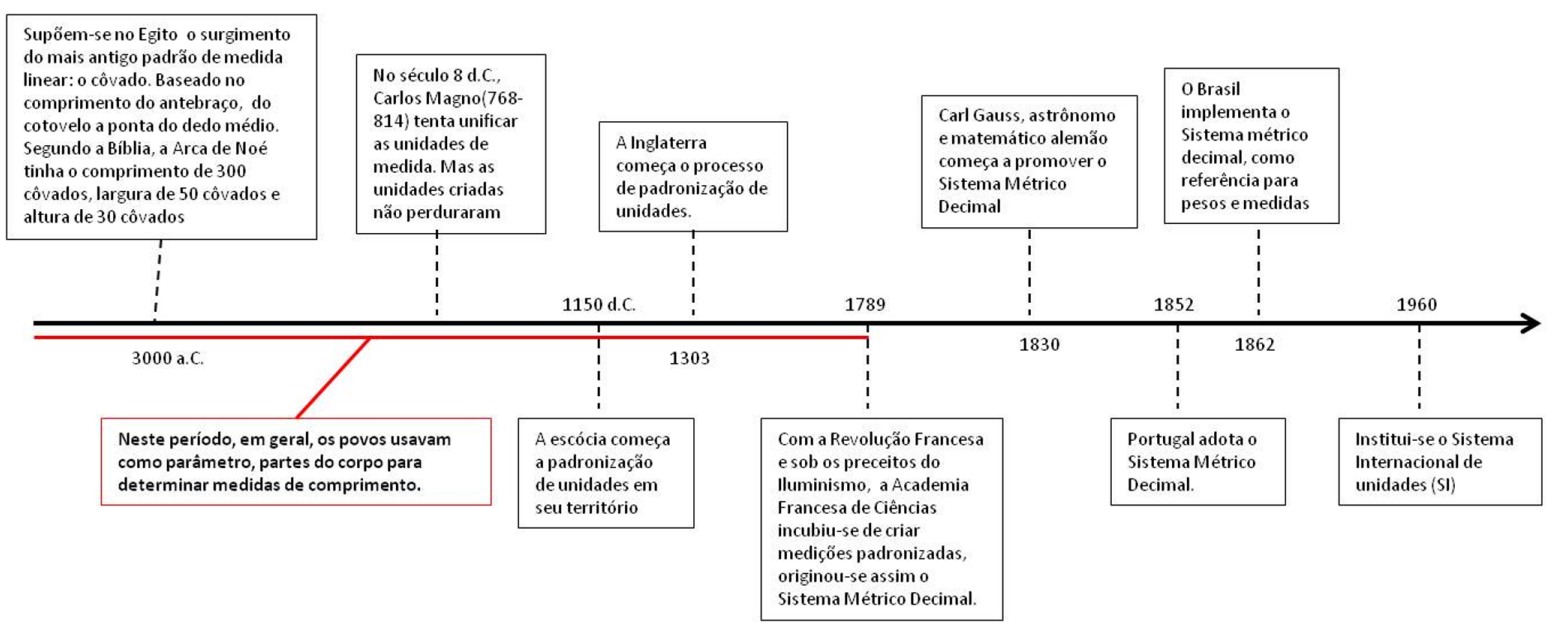

Figura 2: As unidades de medida através dos tempos

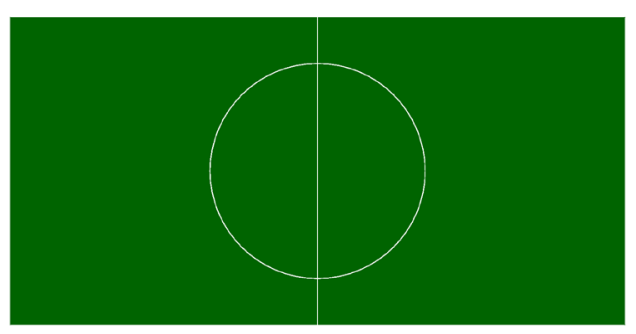

Figura 3: Questão 1

c) Calcule o valor numérico da função $Q(x)$ em $\mathrm{cm}$, onde $x$ é a medida do seu pé. Após, converta o resultado obtido para ft.

d) Calcule o valor numérico da função $D(x)$ em $\mathrm{cm}$, onde $x$ é a medida do seu pé. Após, converta o resultado obtido para $\mathrm{ft}$.

e) Calcule o valor numérico da função $R(x) \mathrm{em}$ $\mathrm{cm}$, onde $x$ é a medida do seu pé. Após, converta o resultado obtido para ft.

f) Calcule o valor numérico da função $C(x)$ em $\mathrm{cm}$, onde $x$ é a medida do seu pé. Após, converta o resultado obtido para ft.

g) Agora substitua $R$ na expressão do comprimento da circunferência $C=2 \pi R$ pelo valor do raio $R(x)$ obtido na letra e).

h) Compare o resultado de g) com o resultado da letra f) e coloque no quadro abaixo a diferença, em $\mathrm{cm}$, entre os resultados obtidos para o comprimento $C$.

Diferença $(C(x)-C)$ em $\mathrm{cm}=$ i) Tomando como referência apenas o raio da circunferência na Figura 3, determine em que escala essa figura está representada.

\section{Escala $=$}

j) Suponha que, em uma determinada escala, a medida do seu pé equivale a $1 \mathrm{~cm}$. Então, nessa escala, calcule o comprimento da circunferência, em cm, obtido na letra f).

Observação 1. Em escolas onde não exista uma quadra de esportes, pode-se construir uma circunferência no chão, nesse caso é interessante usar um pedaço de giz amarrado a um barbante de comprimento desejado, que servirá de raio para a circunferência.

Proposta de Intervenção Social: sugerimos elaborar um projeto de pesquisa para analisar a mobilidade urbana da cidade onde o aluno reside. De posse de um mapa da cidade, com escala gráfica, o aluno deve investigar e apresentar, quais os menores trajetos de sua residência até:

- O hospital, ou o posto de saúde ou uma Unidade de pronto atendimento (UPA);

- A escola onde estuda;

- O posto de polícia militar ou civil;

- A praça pública.

Questão 2. De acordo com a proposta de intervenção social, o professor poderá:

a) Solicitar ao aluno o seu ponto de vista sobre a localização dessas unidades, para saber se elas ocupam lugares estratégicos. Em caso de negação, pedir ao aluno que marque no 
mapa onde seria o ponto favorável para a localização delas.

b) Solicitar ao aluno uma proposta de obra pública (nova rua, viaduto, passarela de pedestres ou ciclovia) indicando em qual ponto da cidade ela deveria ser feita e quais seriam os beneficios gerados no que diz respeito à mobilidade urbana da cidade.

Proposta de continuidade dos estudos: sugerimos que o Professor de História que participar dessa atividade solicite aos alunos um trabalho de pesquisa, para entrega posterior, a respeito da Revolta do Quebra-quilos que ocorreu na região Nordeste do Brasil, no fim de 1874 e meados de 1875, causada pela insatisfação da população com o decreto que em 1872 impunha no Brasil a implantação do Sistema Métrico Decimal.

Jovens no mercado de trabalho: nessa atividade, predomina a ideia investigativa, exigindo um olhar clínico do estudante para situações do seu cotidiano. Iniciamos incentivando o aluno a fazer medições e estabelecer relações entre elas e partimos para medidas menos usuais, como a dos mapas. Após localizar os principais pontos da cidade no mapa e concluir se sua localização é boa ou ruim em termos estratégicos, incentivamos o pensamento crítico e também a construção de uma opinião fundamentada. A capacidade crítica de julgar se a implementação de uma técnica ou projeto será benéfico a uma empresa é qualidade importante para os funcionários e quando, o funcionário a possui, certamente destaca-se em relação aos demais. Por isso acreditamos que a prática dessa atividade preparará o estudante para situações reais que ele enfrentará na rotina de trabalho.

\subsection{O que há por trás das sombras?}

Nesta atividade, relacionamos a Matemática, a História e a Física. Inicialmente, os professores apresentam os temas propostos em cada área, de preferência, na forma de debate. De modo a despertar a curiosidade dos alunos, sugerimos que os professores apresentem o vídeo Matemática em toda parte (2012) que relata como Tales de Mileto descobriu a altura da pirâmide de Quéops no Egito.

Depois da apresentação do vídeo, os professores envolvidos nessa atividade podem apresentar o conteúdo correspondente a cada disciplina.

Após a exposição dos conteúdos, no que se refere à Matemática, sugerimos que o aluno realize uma aula prática usando a proporção existente entre a sua altura e sua sombra para calcular alturas desejadas no pátio da escola, ou fora dela, conforme o interesse do professor.
Depois da aula prática, os alunos retornam para a sala de aula para responder ao caderno de exercícios complementares sugerido pelo professor com o objetivo de preparar o aluno para provas de vestibulares e ENEM. Sugerimos o mesmo como proposta de continuidade de estudos também para as disciplinas de Física e História.

Como Proposta de Intervenção Social lançamos um projeto de pesquisa na análise da inclinação das rampas de acesso aos portadores de necessidades especiais, presente na cidade onde reside o estudante, para averiguar se essas rampas satisfazem as normas impostas pela Associação Brasileira de Normas Técnicas. Essa referência encontra-se em ABNT (2004). Essa proposta encaixa-se na prática de Seminários Integrados no eixo transversal que trata de Direitos Humanos.

Descrição da atividade: um fato interessante na história da matemática foi o cálculo da altura da pirâmide de Quéops no Egito, pelo matemático e filósofo grego Tales de Mileto (690 a 540 a.C.). Cada disciplina abordará os seguintes aspectos:

\& Matemática: estudaremos razão e proporção entre grandezas. Precisamente, a proporção entre a medida da altura e a medida da sombra do corpo humano será usada para calcular a altura de outros objetos cuja medida da sombra é conhecida.

\& História: faremos um estudo da história no Egito Antigo, com ênfase a importância no Rio Nilo, a formação da Sociedade, a Economia, a Religião e, por fim, a Mumificação.

\& Física: estudaremos o princípio de propagação retílinea da luz, os tipos de fontes de luz e a formação de sombra e penumbra.

\section{Objetivos:}

Estudar semelhança de triângulos, razão e proporção;

Com o uso de proporções calcular a altura de um colega e de objetos quaisquer presentes no pátio de nossa escola;

Incentivar o aluno a resolver problemas relacionados ao cotidiano com os conceitos estudados;

Mostrar como, mesmo em um período remoto, a Civilização Egípcia era detentora de conhecimentos na área de ciências, matemática e medicina;

Analisar a formação de imagens em uma câmara escura de orifício, e posteriormente, efetuar alguns cálculos de medidas gerados nas situações. 
Material necessário para a realização dessa atividade: quadro branco, régua, lápis e borracha, fita métrica ou trena (uma para cada dupla de alunos).

Teorema 1 (Semelhança de triângulos). Dois triângulos $\triangle A B C$ e $\triangle D E F$ são semelhantes quando satisfazem uma das seguintes propriedades:

a) Os ângulos em vértices correspondentes são congruentes, ou seja, $\measuredangle A \cong \measuredangle D, \measuredangle B \cong \measuredangle E$ e $\measuredangle C \cong \measuredangle F$.

b) A razão entre as medidas dos lados correspondentes é a mesma, ou seja, $\frac{A B}{D E}=\frac{B C}{E F}=\frac{A C}{D F}=k$.

c) Os triângulos possuem um par de lados consecutivos respectivamente proporcionais e o ângulo formados por esses lados é congruente, ou seja, $\frac{A B}{D E}=\frac{B C}{E F}$ e $\measuredangle B \cong \measuredangle E$.

A Figura 4 mostra dois triângulos semelhantes, pois $\measuredangle A \cong \measuredangle D, \measuredangle B \cong \measuredangle E$ e $\measuredangle C \cong \measuredangle F$.

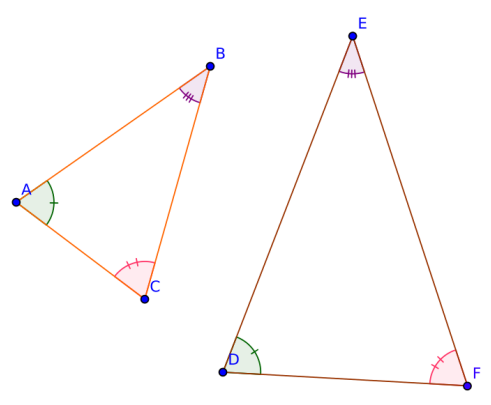

Figura 4: Dois triângulos semelhantes

A razão entre os lados correspondentes dos triângulos é chamada de razão de semelhança e denotada por $k$. Quando $k=1$, os triângulos são ditos congruentes.

Motivação: Nas situações descritas a seguir, podemos usar semelhança de triângulos para encontrar as medidas desejadas.

SITUAÇÃO 1: A Figura 5 mostra que em um mesmo instante (10h da manhã, por exemplo), os raios solares, o prédio e sua sombra determinam um triângulo retângulo. Os ângulos agudos do triângulo retângulo em questão variam de acordo com a inclinação dos raios solares, conforme a Figura 6.

Em dois prédios vizinhos, apesar das alturas serem distintas, como mostram as Figuras 7 e 8, temos o mesmo ângulo de inclinação dos raios solares em um determinado instante. Dizemos que os dois

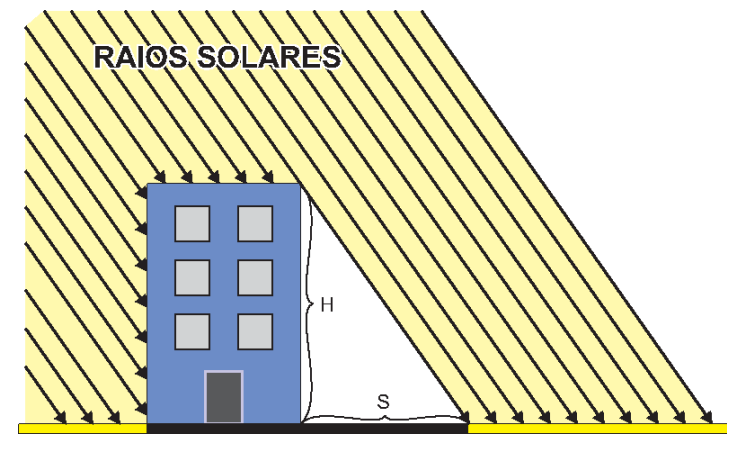

Figura 5: Prédio de altura $H$ e sombra $S$ às $10 \mathrm{~h}$

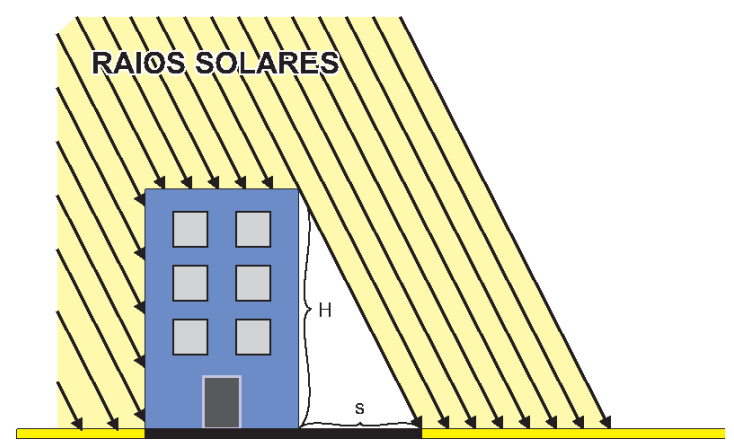

Figura 6: Prédio de altura $H$ e sombra $s$ às $11 \mathrm{~h}$

triângulos retângulos são semelhantes, pois possuem os três ângulos internos (respectivamente) congruentes. Da semelhança entre os triângulos segue a proporção (1).

$$
\frac{H}{h}=\frac{S}{s}=\frac{R}{r} .
$$

Portanto, se conhecemos a altura de um dos pré-

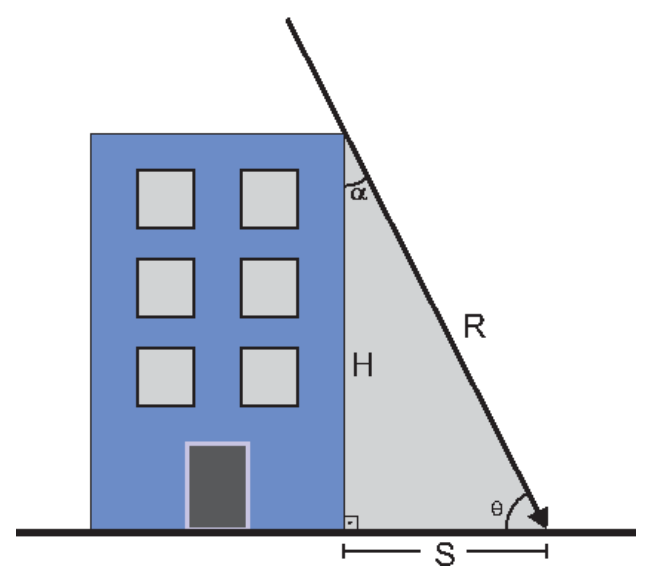

Figura 7: Prédio de altura $H$ e sombra $S$ 


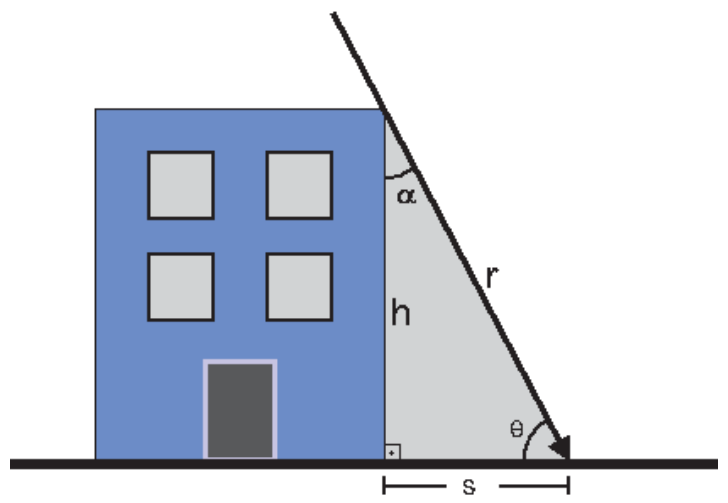

Figura 8: Prédio de altura $h$ e sombra $s$

dios e o comprimento das sombras $s$ e $S$, podemos calcular a altura do outro prédio usando a relação (1).

SITUAÇÃO 2: A Figura 9 apresenta uma árvore e uma pessoa.
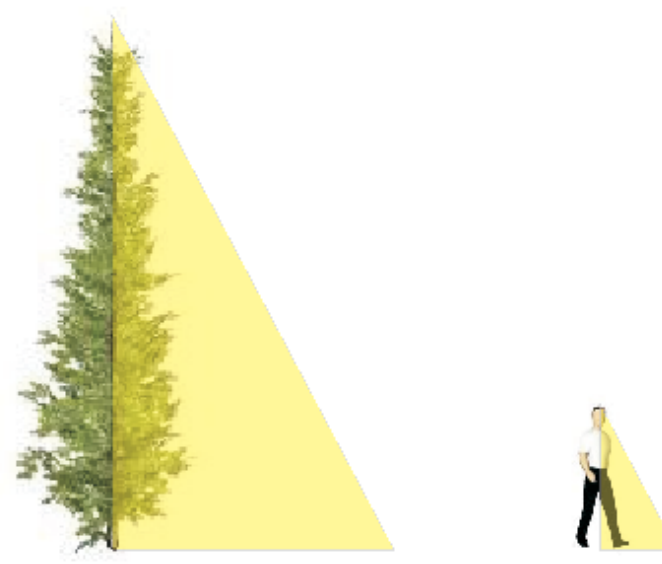

Figura 9: Ilustração da Situação 2

É possível calcular a medida exata da altura da árvore, desde que sejam conhecidas a altura da pessoa e o comprimento das duas sombras, através da relação:

$$
\frac{\text { altura da árvore }}{\text { altura da pessoa }}=\frac{\text { sombra da árvore }}{\text { sombra da pessoa }} \text {. }
$$

Usaremos como referência a proporção existente entre a medida da altura de uma pessoa e a medida de sua sombra, para calcular alturas de objetos quaisquer, sabendo a medida da sombra deles.

\section{Questões Propostas:}

Questão 3. Escolha um colega que será seu auxiliar nesta tarefa.

a) Com a ajuda do colega e usando a fita métrica obtenha a medida da sua própria altura e sombra. Meça a sombra do colega também. Com esses dados use a proporção (2) para determinar a medida da altura dele.

b) Faça um esboço da situação.

c) Compare o resultado obtido com a medida real completando o quadro abaixo.

\section{Altura obtida $=$}

\section{Altura real $=$}

Questão 4. Escolha um objeto qualquer do pátio da escola que servirá como referência nesta tarefa.

a) Usando a fita métrica, encontre a altura do colega e a medida da sua sombra. Use a proporção (2) para determinar a medida da altura do objeto escolhido, sabendo a medida de sombra do mesmo.

Altura obtida $=$

b) Faça um esboço da situação.

Questão 5. Nosso objetivo agora será encontrar a altura do ponto mais alto do prédio da escola.

a) Usando a fita métrica, encontre a altura do colega e a medida da sua sombra. Encontre também a medida da sombra do prédio, em seguida, por meio da proporção (2), calcule a altura do prédio.

b) Faça um esboço da situação.

c) Agora que você possui a altura real do prédio, determine em que escala está o esboço da situação feita no item $b$.

Observação 2. Para cada cálculo que será feito nessa atividade deve-se sempre medir a sombra do colega escolhido, pois lembre-se que mudando o horário haverá uma pequena mudança na inclinação dos raios solares e consequentemente uma alteração na medida da sombra.

Observação 3. Esta atividade pode estender-se para fora dos portões da escola. Uma sugestão de atividade de campo é determinar a altura de prédios históricos ou monumentos importantes da cidade.

Proposta de continuidade dos estudos: sugerimos que os professores de História e Física que participarem dessa atividade, desenvolvam e apliquem aos alunos um questionário, abordando o conteúdo estudado. 
Proposta de intervenção social: propomos que seja elaborado um projeto de pesquisa para analisar as rampas de acesso aos portadores de necessidades especiais presentes nas cidades, com o objetivo de verificar se estas apresentam o coeficiente de inclinação dentro do limite permitido pela Associação Brasileira de Normas Técnicas, o documento base encontra-se disponível em ABNT (2004).

Jovens no mercado de trabalho: segundo Soarez (2010), muito mais que conhecimento, o colégio precisa criar oportunidades para que seus alunos desenvolvam atitudes. Destaca-se também a ideia que os jovens não estejam sendo estimulados a fazer a correlação: vida cotidiana no colégio x vida futura no mercado de trabalho.

Dessa forma, quando deixamos o aluno à vontade para fazer escolhas, compartilhar conhecimento, debater ideias e trabalhar em equipe, estamos preparando o aluno para situações que ele enfrentará no mercado de trabalho.

\subsection{Por quanto tempo um medicamento age em nosso organismo?}

Nesta atividade relacionamos a Matemática, a Química e a Biologia. Inicialmente, os professores podem apresentar aos alunos o vídeo Salvador, o hipocondríaco, UNICAMP (2011) para despertar o interesse deles a respeito do processo de meia-vida dos medicamentos no corpo humano. Após a apresentação do vídeo, sugerimos que os professores envolvidos apresentem os temas de cada área. Novamente essa apresentação deve ocorrer na forma de debate.

Em seguida, propomos que o aluno participe de uma aula prática construindo o gráfico da meia-vida de um medicamento.

Após a aula prática, os alunos devem responder um caderno de exercícios complementares que pode ser elaborado pelo professor, para prepará-los para provas de vestibulares e ENEM. Sugerimos o mesmo para as disciplinas de Biologia e Química.

Como proposta de intervenção social lançamos um projeto que torna a escola um ponto de coleta para as Farmácias Solidárias, que se encaixa no eixo transversal Prevenção e Promoção da Saúde.

Descrição da atividade: estudaremos como ocorre a reação dos medicamentos no organismo e a eficácia deles no combate aos tipos de doenças. Cada disciplina abordará os temas listados a seguir.

\& Matemática: estudaremos o conceito de função linear e exponencial, bem como a construção de suas representações gráficas.
* Química: estudaremos o conceito de radioatividade. Além disso, como funciona o processo de meia-vida dos medicamentos e sua composição química.

* Biologia: distinguiremos doenças virais de bacterianas e estudaremos os modos de transmissão e as formas de tratamento.

\section{Objetivos:}

Estudar a função linear e a função exponencial em um contexto relacionado à saúde;

Analisar o significado dos termos pico de concentração e meia-vida dos medicamentos;

Analisar a composição química dos medicamentos que serviram de base na aplicação dessa atividade;

Apresentar aos alunos doenças causadas por vírus e bactérias, como ocorre a transmissão e tratamento adequado;

Conscientizar os alunos dos perigos envolvendo a automedicação.

Material necessário para a realização dessa atividade: quadro branco, projetor multimídia, régua, lápis e borracha.

Definição 2 (Função linear). Uma função polinomial do $1^{\mathrm{o}}$ grau da forma $f(x)=a x+b$, é dita linear quando $b=0$, ou seja, $f(x)=a x, a \in \mathbb{R}$ e $a \neq 0$. O número $a$ é chamado de taxa de variação da função linear. As Figuras 10 e 11 mostram as possíveis representações gráficas para esse tipo de função.

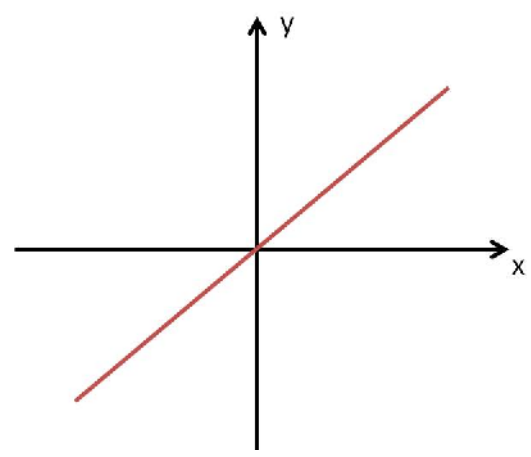

Figura 10: Função Linear Crescente: $a>0$

Definição 3 (Função exponencial). A função $f: \mathbb{R} \rightarrow \mathbb{R}$ dada por $f(x)=a^{x}$ (onde $a \in \mathbb{R}, a>0$ e $a \neq 1$ ) é denominada função exponencial na base $a$.

As representações gráficas da função exponencial encontram-se nas Figuras 12 e 13. 


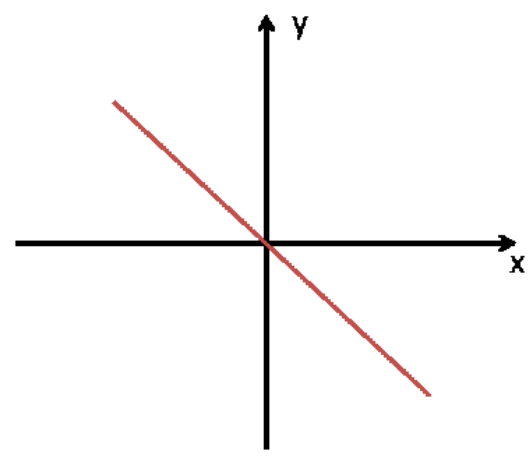

Figura 11: Função Linear Decrescente: $a<0$

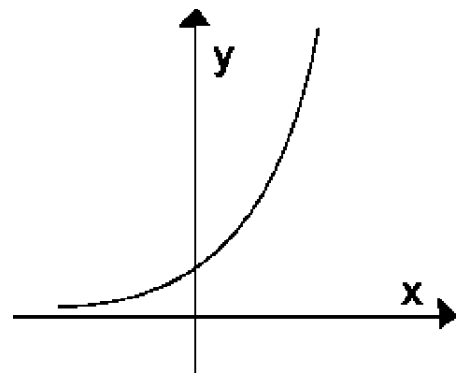

Figura 12: Função exponencial crescente: base $a>1$

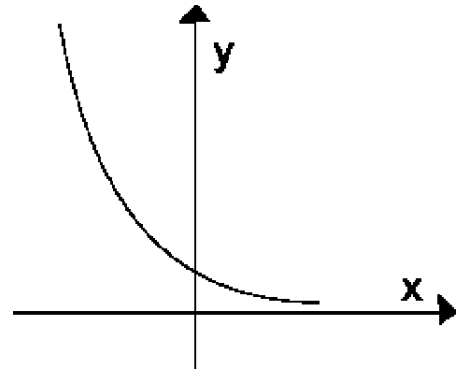

Figura 13: Função exponencial decrescente: base $0<$ $a<1$

Definição 4 (Meia-vida). A meia-vida $\left(t_{1 / 2}\right)$ de um medicamento é o tempo necessário para que a quantidade dele se reduza à metade no organismo.

Texto base: Existe um padrão de eliminação de medicamentos pelo organismo. Algumas substâncias são eliminadas mais rapidamente que outras e esta rapidez de eliminação depende da meia-vida de cada substância. Tratando-se de medicamentos costuma-se dizer que a meia-vida é o tempo necessário para que a concentração plasmática do medicamento no organismo se reduza à metade. A meia-vida permite que se obtenha uma boa estimativa do tempo necessário para que ele seja removido do organismo. Por exemplo, se a quan- tidade que encontramos de um certo fármaco no organismo é de 100mg e que sejam necessários 20 minutos para que esta quantidade chegue a $50 \mathrm{mg}$, temos então que a sua meia-vida é de 20 minutos.

Depois da retomada dos conceitos necessários, é interessante expor aos alunos o vídeo intitulado Salvador, o Hipocondríaco que fala sobre como funciona o processo de meia-vida dos medicamentos em nosso organismo, disponível em UNICAMP (2011).

Questões Propostas: Nessa atividade a turma deverá dividir-se em grupos de 3 alunos, para a discussão e consequentemente construção, conforme a Figura 14, do gráfico da meia-vida do medicamento Amoxicilina, conforme os dados fornecidos a seguir.

\section{A farmacocinética do medicamento Amoxicilina $400 \mathrm{mg}$.}

Segundo ANVISA (2001), a amoxicilina tem absorção digestiva rápida e quase completa, não influenciada pela presença de alimentos no estômago. Induz rapidamente níveis teciduais elevados. Os picos séricos são de $\mathbf{1}$ e $\mathbf{2}$ horas para formulações líquidas e sólidas, respectivamente. Uma hora após administração de dose única de 400 mg (comprimido mastigável ou suspensão), o pico sérico varia entre 5 a 6 microgramas $/ \mathrm{ml}$. Difunde-se bem aos tecidos e fluidos orgânicos, com exceção do líquor, a não ser que haja meninges inflamadas. Ligação a proteínas de $17 \%$ a $20 \%$. Volume de distribuição de 0,26 a 0,31 1/kg. Excreta-se na urina (80\% em forma não modificada), onde se encontra em concentrações mais altas que as plasmáticas. Sua meia-vida é de 1-2 horas. Em neonatos a meia-vida é de 3,7 horas.

Questão 6. Analisando o texto sobre a amoxicilina, podemos perceber que o pico sérico ou o pico de concentração é variante, do mesmo modo que a meia-vida. Portanto, vamos estipular que o pico de concentração ocorre 1 hora após a ingestão do medicamento e que este é de $10 \mu \mathrm{g} / \mathrm{ml}$ e a meia-vida de eliminação será de 2 horas. Assim sendo, construa o gráfico desta função.

Na Figura 14, ilustramos a solução da questão 6.

Observação 4. É importante destacar que nessa atividade estamos analisando a ingestão de apenas uma dose do medicamento. Sabemos que em muitos tratamentos de doenças são necessárias várias doses. A administração em intervalos regulares, sob prescrição médica, tem por objetivo à manutenção da concentração do medicamento no sangue em uma determinada faixa. 


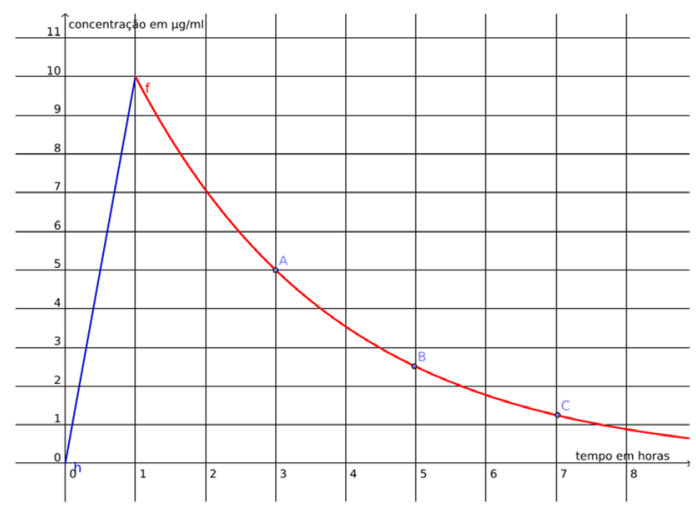

Figura 14: Gráfico da Meia-vida da Amoxicilina

Observação 5. Nessa atividade apresentamos apenas um medicamento para a análise e construção do gráfico. Podemos trabalhar com vários medicamentos, que possuam tempos de pico de concentração e meia-vida diferentes, e depois da confecção do gráfico, por parte dos alunos, pedir que apresentem o resultado obtido para a turma. Em casos onde ocorram valores fracionados para o pico de concentração e período de meia-vida, é importante que o professor intervenha e estipule os valores a serem trabalhados. Essa intervenção justifica-se, pois sabemos que valores fracionados podem dificultar bastante a obtenção da função exponencial.

Proposta de continuidade dos estudos: sugerimos aos professores de Matemática, Química e Biologia que participarem dessa atividade, que elaborem um caderno de exercícios complementares com o objetivo de preparar dos alunos para as provas do ENEM e vestibulares.

Proposta de intervenção social: gostaríamos de transformar a escola em um posto de coleta de medicamentos, para posteriormente serem doados às Farmácias Solidárias. A Farmácia Solidária está presente na grande maioria das cidades do país e tem por objetivo arrecadar as sobras de medicamentos de usuários que não os utilizam mais, mas que ainda estão dentro do prazo de validade, e repassá-los gratuitamente para a população carente da Cidade.

Jovens no mercado de trabalho: o artigo publicado pela revista ISTO É, Rubin (2012), aponta o perfil de profissional que o mercado quer. Segundo esse artigo, "O mundo do trabalho vive sua maior transformação desde a Revolução Industrial e busca um novo tipo de pessoas. Agora o que vale mais é ter formação diversificada, ser versátil, autônomo, conectado, solidário e dono de um espírito crítico e empreendedor".

Nossa atividade valorizou mais uma vez a formação diversificada com a abordagem de três conteúdos curriculares, incentivando a produção autônoma do aluno. Por fim, de modo peculiar, destacamos o espírito solidário desenvolvido na Proposta de Intervenção Social.

\section{Relato da Aplicação das Ativida- des e Discussão dos Resultados}

É importante destacar que a Atividade da subseção 5.1 quando aplicada, foi feita apenas com a disciplina de Matemática. Isto ocorreu em função de uma certa resistência por parte dos professores das disciplinas de História e Geografia, uma vez que a ideia era nova na escola.

Depois que explanamos no quadro branco os conteúdos que estavam sendo estudados com essa atividade, convidamos os alunos a deixar o espaço físico da sala de aula, para irem até a quadra de esportes da escola.

Após efetuarem as devidas medições na quadra de esportes, os alunos retornaram à sala de aula, para individualmente realizarem os cálculos solicitados.

Dos vários itens que foram abordados, um deles chamou a atenção dos alunos. No item a da questão 1, pedimos que eles efetuassem a razão $\frac{C(x)}{D(x)}$. Após alguns terem feito esse cálculo, perguntamos que valores estavam obtendo e as respostas foram: 3,8; 3,18; 3,10; e de imediato, um deles questionou o professor se esse seria aproximadamente o valor de $\pi$. Notamos em muitos deles um semblante de surpresa.

É claro que esperávamos essa afirmação, mas o seu tom precisa ser encarado com estranheza, pois tratavase de uma turma de terceiro ano do Ensino Médio, e muitos deles ainda não compreendiam o significado do valor de $\pi$.

O gráfico da Figura 15 mostra a distribuição percentual entre os alunos, conforme os valores obtidos, para o item 1.

A aplicação da atividade da subseção 5.2 foi feita sem a participação das disciplinas de Física e História. A escola onde essas atividades foram aplicadas possuía duas turmas de terceiro ano do Ensino Médio. Para tentar medir um ganho de aprendizagem, realizamos a parte prática com apenas uma.

Iniciamos com a apresentação formal do conteúdo no quadro branco, sem a realização de exemplos problematizadores, a fim de gerar no aluno o ímpeto de investigação necessária para resolver problemas. Pois bem, realizamos isso com as duas turmas, mas apenas uma delas foi convidada a sair do espaço físico da sala 


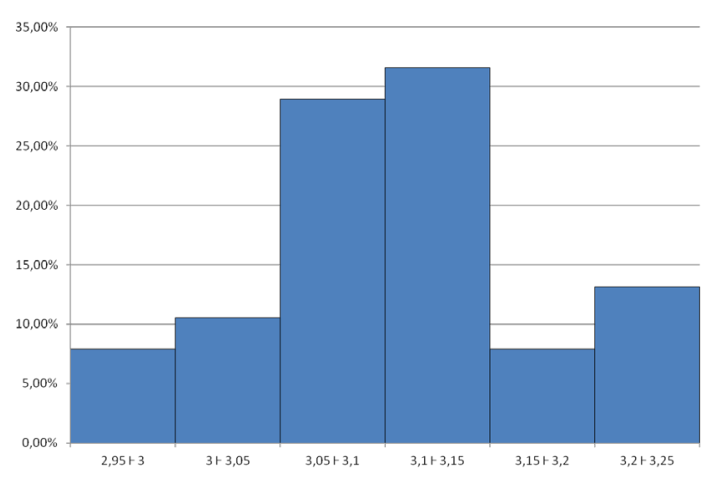

Figura 15: Distribuição percentual dos alunos

de aula, para a atividade prática, como mostra a Figura 16.

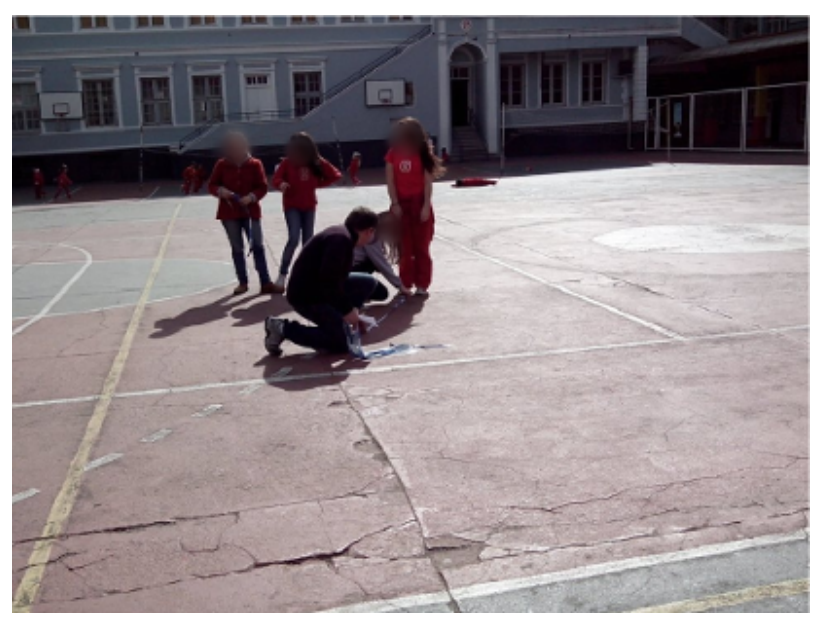

Figura 16: Medindo as sombras, Atividade da subseção 5.2

Com o término da atividade, fornecemos às duas turmas (lembrando que uma delas não realizou a parte prática) 10 questões, para que efetuassem a resolução em um período de 50 minutos, que tratavam do conteúdo estudado. $\mathrm{O}$ resultado com o percentual de acerto por questão, nas duas turmas, aparece na Figura 17.

De acordo com o gráfico da Figura 17, ocorre uma ligeira melhora na resolução de exercícios por parte dos alunos que realizaram atividades práticas. Isto mostra que o conhecimento teórico aliado à prática pode melhorar o aprendizado dos alunos. Surpreendente nessa atividade prática foi a disposição dos alunos para efetuarem as medições e cálculos. Notamos que de certa forma, eles se sentiam desafiados a encontrar a medida exata da altura do colega, bem como do objeto que eles escolheram. Quanto a altura do ponto mais alto da escola, foi interessante notar a troca dos resultados obtidos e a curiosidade gerada nessa atividade. Com todo esse interesse, o lado investigativo despertado no aluno em

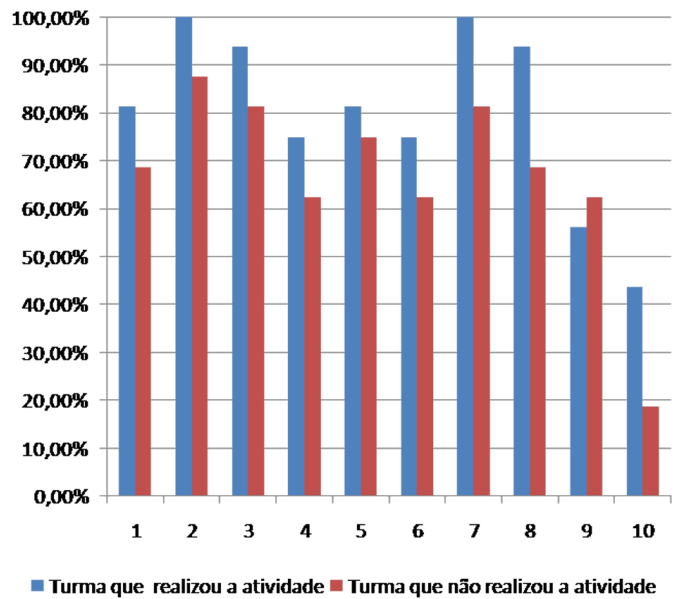

Figura 17: Percentual de acertos por questão: exercícios complementares da Atividade da subseção 5.2

conjunto com os dados mostrados no gráfico da Figura 17 percebemos o quanto a prática auxilia no processo de aprendizagem.

Aplicamos a atividade da subseção 5.3 com a participação das disciplinas de Matemática e Química. Os alunos das turmas foram reunidos em único ambiente para essa aula. Dessa vez, ocupamos o auditório da escola. É importante salientar que, como a escola em questão é particular, a reunião das turmas ocorreu a pedido da Coordenação, para diminuir os custos dessa aula.

Iniciamos apresentando aos alunos o vídeo Salvador, o Hipocondríaco. Após, entregamos aos alunos a atividade impressa (sem a solução) para que eles acompanhassem nesse material o andamento da aula. Em slides retomamos os conceitos de função exponencial e função linear, bem como suas representações gráficas.

O professor de Química leu o texto que encontrase na Atividade da subseção 5.3 e também fez uma explanação a respeito de radioatividade e a composição química dos medicamentos amoxicilina e ibuprofeno.

Aproveitamos para relatar aos alunos os perigos envolvendo a automedicação. Diante de tudo o que expomos, para tentar medir o aprendizado por parte dos alunos, dividimos os alunos em trios e solicitamos que em conjunto fizessem a leitura da bula do medicamento amoxicilina e por conseguinte produzissem, de maneira conjunta, o gráfico do comportamento desse fármaco no organismo. Na Figura 18 destacamos o material produzido por um dos alunos.

Juntamente com a atividade, entregamos aos alunos um questionário com 8 questões organizadas em grau de dificuldade, para que os alunos resolvessem ali mesmo, na aula, em um período de 50 minutos.

Estes exercícios foram usados como método avalia- 


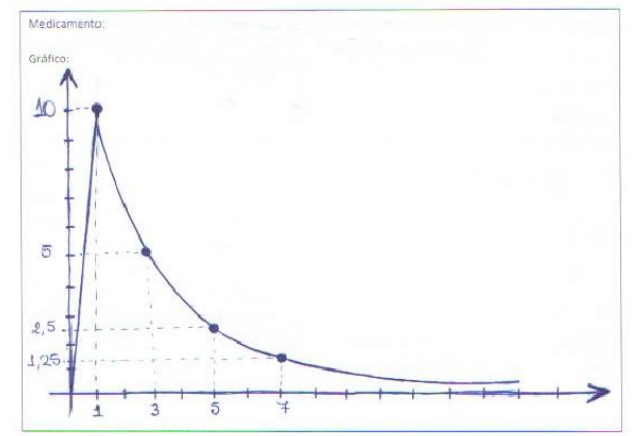

Figura 18: Produção do gráfico da meia vida do medicamento amoxicilina, Atividade da subseção 5.3

tivo em Matemática. O percentual de acertos por aluno mostrou-se satisfatório, acima da média que eles obtinham em outras avaliações.

Os alunos mostraram-se novamente participativos na realização dessa prática. $\mathrm{O}$ trabalho em conjunto favoreceu o diálogo, a troca de ideias e opiniões. Como a maioria das questões envolviam a análise de dados ocorreu entre os discentes uma acalorada discussão.

Novamente percebemos que é mais fácil instigar a curiosidade e o interesse do aluno quando a aula ocorre em conjunto com outros professores, nesse caso em especial, porque muitas vezes ele que não se relaciona bem com a Matemática pode ter uma afinidade com a Química, ou vice-versa. Dessa forma conseguimos chamar a atenção dele e motivá-lo aos estudos, o que provavelmente com uma das disciplinas, de maneira isolada, não conseguiríamos.

O professor de Química, prontamente colaborou quando convidado a manifestar sua opinião sobre a atividade. Em seu relato, ele diz que:

Com a aula que elaboramos percebi que é muito importante para os alunos trabalhar a interdisciplinaridade, devido este ser um processo de interação entre o conhecimento racional e o conhecimento contextualizado e de interação entre saberes tão diferentes. Conseguimos trabalhar conceitos muito distintos em uma única aula e o mais interessante foi notar que com o nosso planejamento em momento algum parecia que estávamos falando de tópicos diferentes, posso afirmar que ocorreu um casamento perfeito entre as disciplinas. No meu ponto de vista a interdisciplinaridade é o caminho pela reconstrução do conhecimento unitário e totalizante do mundo frente a fragmentação do saber. Na escola, essa noção precisa ser materializada em práticas atra- vés da interação de conteúdos e a interação entre ensino e pesquisa.

Também nesse relato, notamos sua preocupação com a forma fragmentada do ensino. Enquanto elaborávamos esta atividade, o professor de Química mencionou que esta seria a sua primeira experiência em trabalhar conteúdos tão distintos em uma mesma aula, como ele menciona em seu relato, mas notamos que este fato não interferiu em nada nossa atividade, bem pelo contrário, compartilhamos de sua opinião quando declara que ocorreu um casamento perfeito entre as disciplinas.

\section{O relato dos alunos}

De um modo geral, os alunos consideraram como muito positivo o estudo de matemática com aulas práticas voltadas para situações do cotidiano e em conjunto com outras disciplinas. Segundo eles, notando-se a relação entre os conteúdos a aprendizagem ocorre de maneira mais fácil.

Outro aspecto importante lembrado pelos alunos é o aumento da aprendizagem quando o conteúdo é ensinado através de associações, como podemos perceber no relato do aluno A:

\footnotetext{
“As atividades do cotidiano - que são práticas — favorecem uma memorização mais adequada e contribuem para uma aprendizagem mais eficiente".
}

A maior parte dos alunos se mostrou bem interessada na realização das atividades práticas. Desde a apresentação feita dos conceitos em sala de aula até a concretização da mesma. A maioria mostrava-se compenetrada, com frequentes questionamentos e troca de opiniões entre si. Acreditamos que, em geral, a motivação dos alunos ocorreu em função das atividades práticas serem contextualizadas e fugirem do padrão convencional de aula a que eles estavam acostumados. Quando questionados sobre as atividades, em relação as aulas, eles responderam:

\begin{abstract}
“O essencial são aulas bem diversificadas, com o conteúdo propriamente dito, desenvolvido no quadro e papel, com outras atividades diversificadas, com aulas práticas, para atender a todo tipo de aluno e suas particularidades. Assim, a aprendizagem seria facilitada, pois haveria mais interesse por parte do aluno.(Aluno B)"
\end{abstract}

Em relação ao professor, o aluno comenta:

\footnotetext{
"Achei muito divertido e mostrou o quanto nosso professor é qualificado, porque nos ensinava a
} 
matéria de forma tradicional e depois nos ajudava a fixá-la realizando essas atividades, mostrandose, assim, muito competente e preocupado com os alunos.(Aluno C)"

Além de despertar o interesse, gerar um conhecimento mais amplo e sólido da realidade para o aluno $\mathrm{D}$, a interdisciplinaridade preparará o jovem para o mercado de trabalho, pois segundo ele:

\begin{abstract}
“O mercado de trabalho atual vem nos mostrando nos últimos anos que um profissional qualificado é detentor de uma visão holística e essa é adquirida por meio do conhecimento em diversas áreas. Além disso, a ideia de interdisciplinaridade estimula os estudos já que impede o cansaço somente em uma matéria específica, contribuindo para a formação de um conhecimento mais amplo e com aplicações práticas".
\end{abstract}

A visão desse jovem vai de encontro às necessidades apontadas pela SEDUC/RS que protagonizaram toda a reformulação proposta no Ensino Médio Gaúcho. Notamos que há por parte dos jovens este anseio e expectativa por uma forma diferenciada de ensino. Com nossas atividades percebemos que conseguimos suprir em parte essa expectativa.

Portanto, na visão dos alunos, é inegável que atividades práticas voltadas à interdisciplinaridade enriquecem de sobremaneira uma aula, tornando-a mais interessante, atrativa e eficaz naquilo que diz respeito ao aprendizado.

\section{Considerações finais}

Entendemos que o ensino de Matemática tem enfrentado diversas dificuldades. Entre elas, está a falta de atividades práticas que proporcionem uma aprendizagem que enfatize a contextualização. Em geral, os alunos são levados a memorizar estratégias de resolução de problemas para reproduzi-las em provas, sem um entendimento de situações cotidianas onde aquela teoria poderia ser aplicada. Dessa forma, com o objetivo de superar esse problema, sugerimos que os professores possam investir em novas metodologias de ensino que valorizem a contextualização e destaquem o aluno como elemento participativo no processo de ensino-aprendizagem.

Iniciamos nosso trabalho com o objetivo de desenvolver atividades contextualizadas que estivessem relacionadas ao corpo humano, mostrando como a matemática não só está relacionada ao cotidiano do aluno, mas também está presente no seu corpo e como este pode ser usado como ferramenta no processo de ensinoaprendizagem.

No decorrer da elaboração das atividades percebemos que a abordagem da Matemática de maneira frag- mentada ficava aquém daquilo que pretendíamos em termos de contextualização. Surgiu então o interesse de convidar outras áreas do conhecimento. Percebemos que nossas atividades, mesmo sendo aplicadas em uma escola particular, podiam ser adotadas como base para a estruturação dos Seminários Integrados, em vigor nas escolas Estaduais. Buscamos assim uma integração entre nossa proposta de ferramenta de ensino e o Ensino Médio Politécnico, e isto ocorreu no enfoque voltado a interdisciplinaridade.

Com relação à elaboração e aplicação das atividades é importante relatar o quanto essas práticas acrescentaram, em termos de experiência profissional, pois serviram como base para um enriquecimento de conteúdo e nos conscientizaram sobre a necessidade da pesquisa do professor. Elas geraram um contato mais próximo com o aluno, facilitando bastante a identificação de suas necessidades que, em alguns casos, era difícil de perceber. Também nos surpreendemos com o pedido dos alunos por mais aulas como esta.

Destacamos também a aproximação com os colegas de trabalho. Todas as conversas informais, reuniões de corredores e cafezinhos, trocas de opiniões, experiências e materiais, geraram, sem dúvida, grande enriquecimento profissional. Comprovação disso foi um convite feito pela direção da escola, onde aplicamos essas atividades, para o autor protagonista deste trabalho desempenhar no ano de 2014 o papel de coordenador de um setor da escola que trataria da integração de disciplinas, com o objetivo de estruturar atividades interdisciplinares.

Ao todo, apresentamos três atividades interdisciplinares que juntas, podem englobar quase todas as disciplinas presentes no currículo do Ensino Médio. Entendemos que elas destacam-se em relação a uma aula tradicional, pois além de fugir da abordagem geralmente adotada, apresentam elementos novos que são: Proposta de Intervenção Social e Jovens no Mercado de Trabalho.

Nossa experiência docente mostra que através do método tradicional dificilmente teríamos alcançado tamanho envolvimento e dedicação dos alunos. O ensino de matemática com atividades contextualizadas e interdisciplinares mostrou-se muito eficiente no que diz respeito a despertar o interesse do aluno, à prática de trabalhos em equipe e a exposição de ideias para convencer colegas sobre determinados pontos de vista, o que até então não era muito comum nas aulas de Matemática.

Para trabalhos futuros, ficamos com o desafio de buscar novas atividades interdisciplinares onde possamos encaixar o corpo humano ou outros assuntos como tema transversal para estudo e pesquisa. 


\section{Referências}

ABNT, A. B. N. T., 2004. Acessibilidade a edificações, mobiliário, espaços e equipamentos urbanos. Associação Brasileira Normas Técnicas, Brasília.

URL http://www.pessoacomdeficiencia.gov.br/ app/normas-abnt

Andrade, R. C., 1994. Interdisciplinaridade - um novo paradigma curricular.

URL http://www2 .ufpa.br/ensinofts/interdisci . html

ANVISA, 2001. Fármacos Utilizados em infecções. Ministério da Saúde, Brasília.

BRASIL, 2000. Parâmetros Curriculares Nacionais: fundamental e médio. Secretaria da Educação Básica, Brasília.

URL http://portal.mec.gov.br/

Fazenda, I. C. A., 2011. Interdisciplinaridade: História, Teoria e Pesquisa. Papirus, São Paulo.

Japiassu, H., 1976. Interdisciplinaridade e Patologia do Saber. Imago, Rio de Janeiro.

Matemática em toda parte, 2012. Tales e a altura da pirâmide.

URL http://www. youtube.com/watch?v= cWkU6fGoYA8

Pereira, S. M., 2012. Implementação do ensino médio politécnico no rio grande do sul: possibilidades de viabilização.

PORTALIDEB, 2014. Ideb e seus componentes: Rio grande do sul.

URL http://www.portalideb.com.br/estado/ 121-rio-grande-do-sul/ideb?etapa=EM\&rede= estadual

Rubin, D., 2012. O profissional que o mercado quer. Revista ISTO É Independente (2212).

Saviani, D., 1989. Sobre a Concepção de Politecnia. Fundaçao Osvaldo Cruz, Rio de Janeiro.

Saviani, D., 2007. Trabalho e educação: fundamentos ontológicos e históricos. Revista Brasileira de Educação Pública, Cuiabá (34).

SEDUC/RS, 2011-2014a. Proposta Pedagógica para o Ensino Médio Politécnico e Educação Profissional integrada ao Ensino Médio - 2011-2014. Secretaria da Educação do Rio Grande do Sul, Porto Alegre.

URL http://www.educacao.rs.gov.br/dados/ens_ med_proposta.pdf
SEDUC/RS, 2011-2014b. Regimento Referência das Escolas de Ensino Médio Politécnico da Rede Estadual 2011-2014. Secretaria da Educação do Rio Grande do Sul, Porto Alegre.

URL http://www.educacao.rs.gov.br/dados/ens_ med_regim_padrao_em_Politec_I.pdf

Silva, M. N. P., 2014. Unidades de medida ao longo da história.

URL http://www.mundoeducacao.com/matematica/ unidades-medida-ao-longo-historia.htm

Soarez, E., 2010. Como preparar os jovens para o mercado de trabalho: Desafios de uma boa educação. URL http://www.acessa.com/educacao/arquivo/ carreira/2010/04/23-artigo/

UNICAMP, 2011. Salvador, O hipocondríaco.

URL http://objetoseducacionais2.mec.gov.br/ handle/mec/17138

Vomero, M. F., 2003. Conheça a fascinante história das medidas, que acompanham o homem desde o tempo das cavernas. 